\title{
PET/MRI Improves Management of Children with Cancer
}

\author{
Lucia Baratto $^{1}$, K. Elizabeth Hawk ${ }^{1}$, Lisa States ${ }^{2}$, Jing Qi $^{3}$, Sergios Gatidis ${ }^{4}$, Louise Kiru ${ }^{1}$, and Heike E. Daldrup-Link ${ }^{1,5}$ \\ ${ }^{1}$ Department of Radiology, Stanford University, Stanford, California; ${ }^{2}$ Department of Radiology, Children's Hospital of Philadelphia, \\ Philadelphia, Pennsylvania; ${ }^{3}$ Department of Radiology, Children's Wisconsin, Milwaukee, Wisconsin; ${ }^{4}$ Department of Diagnostic and \\ Interventional Radiology, University Hospital Tübingen, Tübingen, Germany; and ${ }^{5}$ Department of Pediatrics, Stanford University, \\ Stanford, California
}

\begin{abstract}
Learning Objectives: On successful completion of this activity, participants should be able to describe (1) why integrated ${ }^{18} \mathrm{~F}-\mathrm{FDG}$ PET/MR can be a time-efficient, convenient, and safe approach for the management of children with cancer; (2) the advantages of integrated ${ }^{18} \mathrm{~F}-\mathrm{FDG}$ PET/MR in the evaluation of children with cancer and predisposition syndromes such as lymphoma, sarcoma, and neurofibromatosis 1; and (3) future research directions for the use of integrated ${ }^{18} \mathrm{~F}-\mathrm{FDG}$ $\mathrm{PET} / \mathrm{MR}$ in children with cancer.
\end{abstract}

Financial Disclosure: This study was supported by a grant from the National Institute of Child Health and Human Development (NICHD, R01HD081123) and the Sarcoma Foundation. The authors of this article have indicated no other relevant relationships that could be perceived as a real or apparent conflict of interest.

CME Credit: SNMMI is accredited by the Accreditation Council for Continuing Medical Education (ACCME) to sponsor continuing education for physicians. SNMMI designates each JNM continuing education article for a maximum of 2.0 AMA PRA Category 1 Credits. Physicians should claim only credit commensurate with the extent of their participation in the activity. For CE credit, SAM, and other credit types, participants can access this activity through the SNMMI website (http://www.snmmilearningcenter.org) through October 2024.

Integrated PET/MRI has shown significant clinical value for staging and restaging of children with cancer by providing functional and anatomic tumor evaluation with a 1-stop imaging test and with up to $80 \%$ reduced radiation exposure compared with ${ }^{18} \mathrm{~F}-\mathrm{FDG} \mathrm{PET} /$ CT. This article reviews clinical applications of ${ }^{18} \mathrm{~F}-\mathrm{FDG}$ PET/MRI that are relevant for pediatric oncology, with particular attention to the value of PET/MRI for patient management. Early adopters from 4 different institutions share their insights about specific advantages of PET/MRI technology for the assessment of young children with cancer. We discuss how whole-body PET/MRI can be of value in the evaluation of certain anatomic regions, such as soft tissues and bone marrow, as well as specific PET/MRI interpretation hallmarks in pediatric patients. We highlight how whole-body PET/MRI can improve the clinical management of children with lymphoma, sarcoma, and neurofibromatosis, by reducing the number of radiologic examinations needed (and consequently the radiation exposure), without losing diagnostic accuracy. We examine how PET/MRI can help in differentiating malignant tumors versus infectious or inflammatory diseases. Future research directions toward the use of PET/MRI for treatment evaluation of patients undergoing immunotherapy and assessment of different theranostic agents are also briefly explored. Lessons learned from applications in children might also be extended to evaluations of adult patients.

Key Words: oncology; pediatrics; PET/MRI; cancer; pediatric oncology

J Nucl Med 2021; 62:1334-1340

DOI: 10.2967/jnumed.120.259747

$\mathbf{T}$ raditional 1-stop imaging tests, such as $\mathrm{CT}$ and $\mathrm{PET} / \mathrm{CT}$, are associated with considerable radiation exposure and risk of secondary cancer development later in life $(1,2)$. This is particularly concerning

Received Nov. 5, 2020; revision accepted May 21, 2021.

For correspondence or reprints, contact Heike E. Daldrup-Link (heiked@ stanford.edu).

COPYRIGHT (C) 2021 by the Society of Nuclear Medicine and Molecular Imaging. for children, as they are more sensitive to radiation effects than adults are. Because advances in cancer therapy have significantly improved survival in pediatric cancer patients, these patients now live long enough to encounter secondary cancers (3-5). Integrated PET/MRI provides cancer staging and restaging with up to $80 \%$ reduced radiation exposure compared with PET/CT by replacing CT with MRI for anatomic colocalization of radiotracer data (6). Although many studies have addressed the technical aspects of a PET/MRI examination, few studies have discussed how PET/MRI can improve patient management compared with standard imaging modalities. For this review article, we have assembled a team of early adopters of pediatric PET/MRI from different backgrounds (radiologists, nuclear medicine physicians, and researchers), different hospitals, and different states or countries who summarize important clinical-translational PET/MRI applications for children with cancer and predisposition syndromes. This article focuses on new developments in the field of PET/MRI, with particular attention to patient management.

\section{CLINICAL APPLICATIONS OF PET/MRI IN CHILDREN WITH CANCER AND NEUROFIBROMATOSIS TYPE 1}

\section{Special Considerations for PET/MRI of Children}

PET/MRI of children under the age of 6 y usually requires sedation or anesthesia to minimize patient motion. A significant benefit of integrated PET/MRI compared with 2 separate examinations for young children is a reduction in the number of sedations, which reduces the risk of related complications, such as aspiration, and adverse neurocognitive effects (7). In addition, the high soft-tissue contrast provided by MRI can help in the differentiation of agedependent normal from abnormal findings.

One of the most common physiologic findings in the pediatric age group is increased ${ }^{18} \mathrm{~F}$-FDG uptake in the Waldeyer ring and cervical lymph nodes. In patients with intrinsic high ${ }^{18} \mathrm{~F}-\mathrm{FDG}$ activity in the Waldeyer tonsillar ring, MRI can help to characterize normal tonsils. Preserved tonsil morphology with homogeneous signal intensity and symmetric ${ }^{18}$ F-FDG uptake is likely benign, whereas globular tonsil 


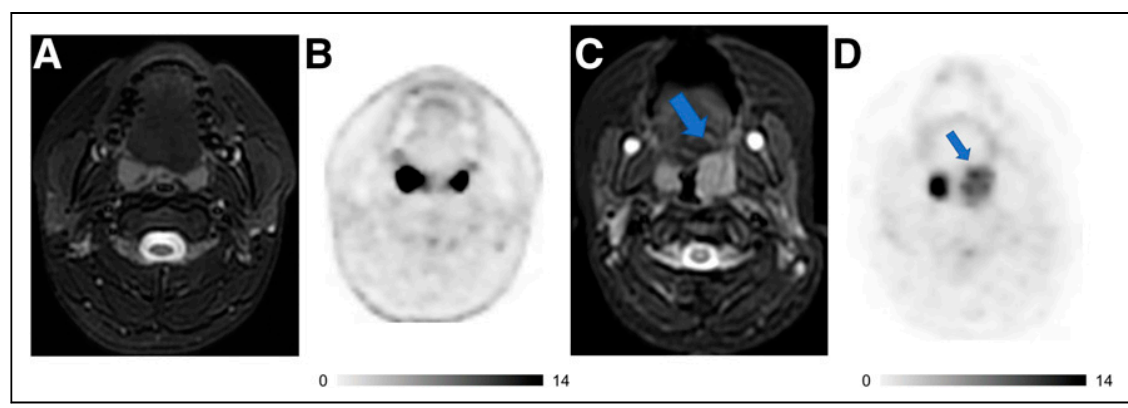

FIGURE 1. ${ }^{18} \mathrm{~F}$-FDG PET/MRI helps to characterize activity in tonsils and stage patients with lymphoma. (A and B) Axial T2-weighted fat-saturated fast-spin-echo (FSE) image (A) and ${ }^{18} \mathrm{~F}$-FDG PET image (B) of 15 -y-old boy with follicular lymphoma show symmetric morphology and marked ${ }^{18} \mathrm{~F}$ FDG uptake of both tonsils with reactive hyperplasia. (C and D) Axial T2-weighted FSE image (C) and ${ }^{18} \mathrm{~F}$-FDG PET image (D) of 4 -y-old girl with large B-cell lymphoma demonstrate asymmetric globular enlargement and relatively less intensive ${ }^{18} \mathrm{~F}-\mathrm{FDG}$ uptake of left tonsil (arrows). Tonsillectomy revealed large B-cell lymphoma in left tonsil and reactive tissue in right tonsil. Intrinsic uptake in tonsi is more avid than lymphomatous involvement on second patient. Radiologists must be cognizant of this caveat and integrate metabolic and morphologic information to increase diagnostic accuracy. high sensitivity for detecting metastatic lesions because of increased water content and increased vascularity; however, sensitivity may be decreased in children with red marrow. The detection of metastases is improved with the addition of ${ }^{18} \mathrm{~F}-\mathrm{FDG}$ $\mathrm{PET}$, which increases the sensitivity from $82 \%$ to $96 \%$ (15). When compared with normal marrow, bone marrow metastases demonstrate increased ${ }^{18} \mathrm{~F}-\mathrm{FDG}$ uptake, low T1 signal (less than muscle or intervertebral disk as internal standards), increased T2 signal, restricted diffusion, increased water content, and increased contrast enhancement on gadolinium-enhanced MRI. Although one of these characteristics might be masked, the rich information from MRI allows for the detection of bone marrow metastases with higher accuracy than is possible with bone marrow biopsies (16).

An example of how information from enlargement or asymmetric ${ }^{18} \mathrm{~F}-\mathrm{FDG}$ activity is concerning for malignancy (Fig. 1)

Prominent benign cervical lymph nodes are common in children. In children, the short-axis diameter is less than $15 \mathrm{~mm}$ for normal level II lymph nodes and less than $10 \mathrm{~mm}$ for all other cervical levels (8). Vali et al. found increased ${ }^{18}$ F-FDG lymph node uptake in $29 \%$ of patients who underwent PET/CT for non-head and neck tumors (9). Benign lymph nodes had a lower $\mathrm{SUV}_{\max }$ than malignant lesions, with a mean $\mathrm{SUV}_{\max }$ of 2.1 and 4.2, respectively. A suggested $\mathrm{SUV}_{\max }$ cutoff for benign lymph nodes was less than 3.2. Diffusion-weighted imaging is helpful for identification of lymph nodes, although it does not outperform size criteria for characterization of malignant nodes (10-12).

The thymus has a variable appearance depending on age, physiology, and treatment status. The normal thymus can be large in young children and will have a homogeneous signal intensity and convex borders in the youngest patients. The borders become straight in older children and concave in adolescents (13). The normal thymus usually has an $\mathrm{SUV}_{\max }$ of less than 4 (14). During chemotherapy, the thymus shrinks because of physiologic stress. Within approximately 12 mo after treatment, there is a recovery phase in which the thymus can enlarge up to 1.5 times the original size and demonstrate increased ${ }^{18}$ F-FDG uptake. This thymic rebound is often accompanied by bone marrow reconversion. MRI can confirm that the thymus has a homogeneous signal and lacks restricted diffusion (13).

Age-related changes are also seen in the pediatric bone marrow. At birth, red marrow is seen throughout the skeleton. An orderly conversion to yellow marrow follows a predicted course and is most easily detected on non-fat-saturated T1-weighted images. During the first year of life, the initial site of conversion to yellow, fatty marrow is the epiphyses of the long bones, followed by the diaphyses in young children and metaphyses in older children. The last change is in the proximal metaphyses of the proximal long bones, with residual red marrow often seen in teens and young adults. The axial skeleton, including the spine and pelvis, converts to red marrow over a slower course. The fluidsensitive, fat-suppressed sequences such as T2-weighted fast spin echo and short-inversion-time inversion recovery, provide
PET/MRI helped in staging a patient is shown in Figure 2.

PET/MRI evaluation of pulmonary lesions is challenging; in fact, diagnostic MRI of the lungs is difficult to perform because of the inherent low proton density in the lungs, resulting in a low signal-to-noise ratio, cardiac and respiratory motion artifacts, and susceptibility artifacts at the tissue-air interface. Hence, for characterization of small pulmonary nodules, additional chest CT may be useful (17).

\section{PET/MRI of Children with Lymphoma}

${ }^{18}$ F-FDG PET is preferred for evaluation of lymphoma (18). Most children with lymphoma have excellent long-term survival (19), and minimizing ionizing radiation exposure is particularly important in these patients. ${ }^{18}$ F-FDG PET/MRI and PET/CT demonstrated equivalent diagnostic performance for detection, classification, Ann Arbor staging, and treatment response assessment of pediatric lymphoma $(6,20,21)$.

There is a strong correlation between PET/MRI- and PET/CTderived SUV. SUVs on PET/MRI based on segmented attenuation maps are lower than those on PET/CT using transmission-based attenuation correction $(6,20,22,23)$. Only a few studies reported higher SUVs on PET/MRI than on PET/CT, and that was attributed to ${ }^{18} \mathrm{~F}$-FDG trapping in the tumor due to an extended uptake time (21). Since differences in SUV occurred in a systematic fashion, they are not clinically relevant as long as the same modality is used for a given patient.

${ }^{18}$ F-FDG PET is superior to core biopsy in the detection of bone marrow involvement (16). Heacock et al. suggested that PET/MRI had an advantage in the detection of bone marrow disease and enhances diagnostic confidence (22). The detection of bone marrow involvement can facilitate earlier aggressive treatment. At some institutions, bone marrow core biopsy can be avoided if PET/MRI is negative for marrow involvement (24).

Sensitivity is lower for ${ }^{18}$ F-FDG PET/MRI than for PET/CT in detecting subcentimeter lung nodules (17); however, lung involvement by lymphoma could be successfully depicted on PET/MRI, because these nodules are typically larger and ${ }^{18}$ F-FDG-avid (21).

\section{PET/MRI of Children with Sarcoma}

For many children with solid malignancies, including pediatric patients with osteogenic and soft-tissue sarcomas, MRI is already 


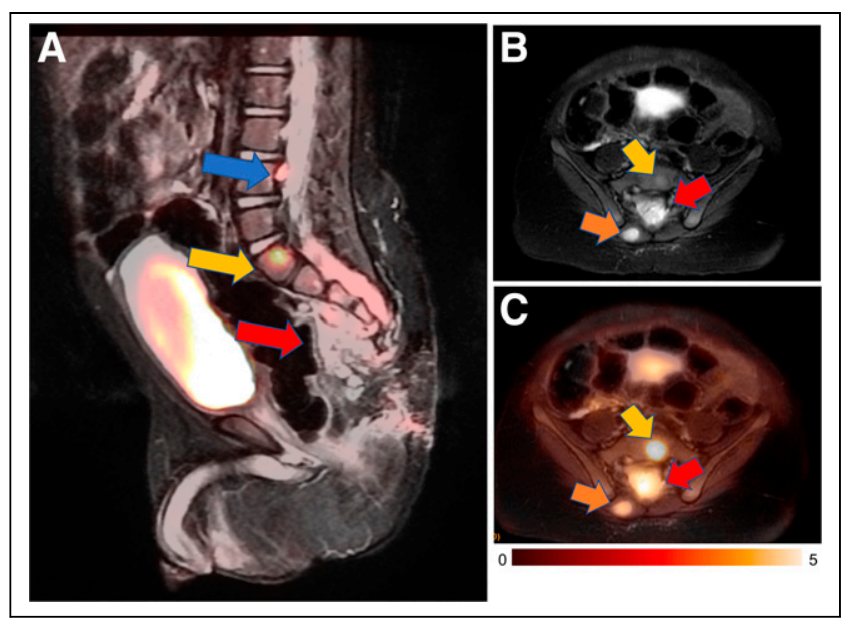

FIGURE 2. ${ }^{18} \mathrm{~F}-\mathrm{FDG}$ PET/MRI detects tumor invasion into spinal canal in 18-mo-old boy with metastasized germ cell tumor. (A) Sagittal short-inversion-time inversion recovery image, fused with simultaneously acquired ${ }^{18} \mathrm{~F}-\mathrm{FDG}$ PET image, demonstrates presacral mass (red arrow), which extends into spinal canal. Also noted is ${ }^{18} \mathrm{~F}$-FDG-avid lesion in $\mathrm{S} 1$ vertebra (yellow arrow) and extradural focus posterior to L4 vertebra (blue arrow). (B) Axial T2-weighted fast-recovery fast-spin-echo fat-saturated image shows soft-tissue mass entering spinal canal (red arrow). Also noted are metastatic lesions in $\mathrm{S} 1$ (yellow arrow) and right paraspinal muscle (orange arrow). (C) Fast-recovery fast-spin-echo fat-saturated image fused with ${ }^{18} \mathrm{~F}$-FDG PET image shows hypermetabolism of all lesions. Information from PET/MRI helped in staging by showing metastatic disease and extent of disease in spinal canal, hence impacting patient management. Patient started chemotherapy right after PET/MRI.

therapy response better than changes in tumor size or MR contrast enhancement $(25,26)$. Patients with sarcomas who responded to chemotherapy demonstrated increasing tumor apparent diffusion coefficient (ADC) values, while nonresponders demonstrated stable or decreasing ADC values (26,27). We discovered that chemotherapy first decreases glucose metabolism and then increases hydrogen proton diffusion in solid tumors (28). At 8-12 wk after the start of therapy, most sarcomas demonstrate an excellent agreement between changes in SUV and apparent diffusion coefficients (29). It is not known if patients with a metabolic response on ${ }^{18} \mathrm{~F}$-FDG PET, but a delayed response on diffusion-weighted imaging, have worse outcomes than patients with a concordant response on both imaging modalities.

PET/MRI can also improve monitoring of pediatric tumors after immunotherapy (29). Cotreatment with drugs that stimulate marrow reconversion (e.g., granulocyte colony-stimulating factor) can mask metastases. Intravenously administered ferumoxytol nanoparticles are taken up by normal bone marrow and not tumor in the early $(0-1 \mathrm{~h})$ postcontrast phase and, thereby, can improve tumor detection $(30,31)$.

In the future, earlier identification of nonresponders might help prevent side effects from ineffective therapies. Osteosarcomas contain high quantities of tumor-associated macrophages (TAM) and have shown an impressive response to TAMtargeted immunotherapies in mouse models (32,33). CD47 monoclonal antibodies activate TAM to phagocytose cancer cells (34-38). Treatment with CD47 monoclonal antibodies significantly inhibited tumor growth and increased survival in mice with bone and soft-tissue sarcomas $(36,39,40)$. We showed that ferumoxytol MRI can detect TAM in oste-

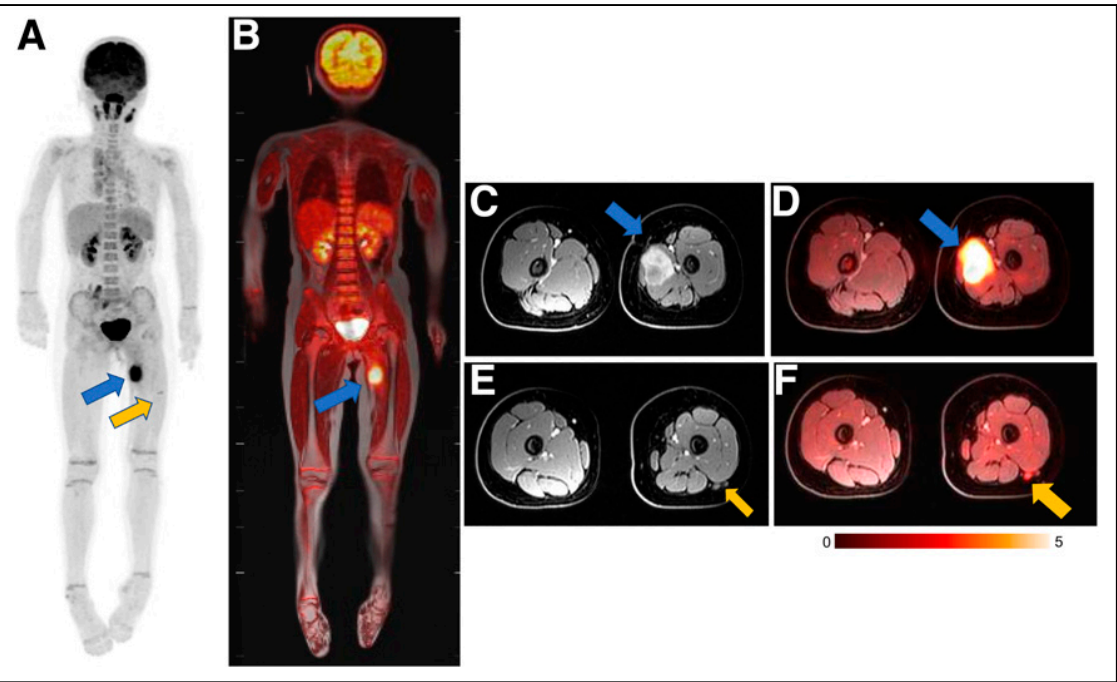

FIGURE 3. ${ }^{18} \mathrm{~F}-\mathrm{FDG}$ PET/MRI accurately stages rhabdomyosarcoma in 9-y-old girl. (A and B) Maximum-intensity projection of ${ }^{18} \mathrm{~F}$-FDG PET scan (A) and ${ }^{18} \mathrm{~F}$-FDG PET/MRI scan (B) show avid ${ }^{18} \mathrm{~F}-\mathrm{FDG}$ uptake in lesion in thigh adductor muscles (blue arrow) and tiny additional ${ }^{18} \mathrm{~F}$-FDG-avid lymph node in lateral thigh (yellow arrow). MRI helps to exclude any bone marrow disease or cortical invasion. (C and D) Axial contrast-enhanced fat-saturated T1-weighted MRI scan (C) and ${ }^{18} \mathrm{~F}-\mathrm{FDG}$ $\mathrm{PET} / \mathrm{MRI}$ scan (D) demonstrate relation between primary tumor (arrow) and superficial and deep femoral artery and vein. ( $E$ and $F$ ) Axial contrast-enhanced fat-saturated $T 1$-weighted $M R I$ scan $(E)$ and ${ }^{18} \mathrm{~F}$ FDG PET/MRI scan (F) demonstrate small lymph node (arrow) posterior to vastus lateralis muscle. Primary tumor and lymph node were resected and positive for sarcoma.

the clinical standard for local staging. In these patients, integrated ${ }^{18}$ F-FDG PET/MRI can provide local and whole-body staging in one session (Fig. 3). Diffusion-weighted MRI can predict tumor osarcomas in mouse models (40) and patients (41) and can monitor TAM response to CD47 monoclonal antibodies (42).

\section{PET/MRI of Children with Neurofibromatosis Type 1}

In patients with neurofibromatosis type 1, which is a cancer predisposition syndrome, MRI provides a detailed depiction of peripheral neurofibromata and central nervous system lesions (43). However, MRI provides limited accuracy in detecting lesion transformation into malignant peripheral nerve sheath tumors (MPNSTs) (44). ${ }^{18} \mathrm{~F}-\mathrm{FDG}$ PET can add information about increased glucose metabolism in MPNSTs (Fig. 4) $(43,45,46)$. Higher ${ }^{18}$ F-FDG uptake has been shown in MPNSTs than in benign neurofibromatosis type 1 lesions, with suggested SUV cutoffs ranging between approximately 2.5 and $6(43,45-48)$.

With respect to MRI, different parameters such as rapid growth, ill-defined margins, and large size have been suggested as potentially discriminative between benign lesions and MPNSTs. (49). Lesion apparent diffusion coefficient can reflect increased cellularity in MPNSTs, with overall inconclusive results regarding its added benefit $(43,44,50)$. Recent studies have also assessed the 


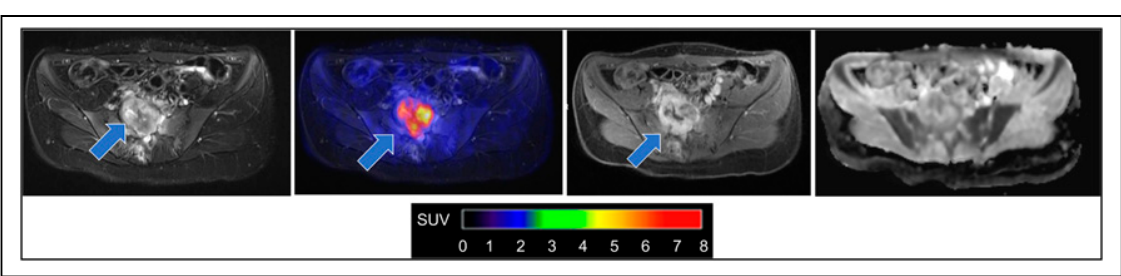

FIGURE 4. ${ }^{18} \mathrm{~F}$-FDG PET/MRI enabled image-informed surgical planning in 21-y-old patient with neurofibromatosis type 1. From left to right: axial fat-saturated T2-weighted image through pelvis reveals heterogeneous lesion infiltrating sacrum (arrow); ${ }^{18} \mathrm{~F}$-FDG PET fused with T2-weighted MRI scan shows increased glucose metabolism of sacral lesion ( $\mathrm{SUV}_{\max }=6$; arrow); axial contrast-enhanced fat-saturated T1-weighted MRI scan shows heterogeneous tumor enhancement (arrow); apparent diffusion coefficient map demonstrates restricted diffusion of lesion with mean apparent diffusion coefficient of $0.85 \cdot 10^{-3} \mathrm{~mm}^{2} \mathrm{~s}$, which is suggestive of MPNST. Curative treatment of MPNST is critically dependent on early detection. Combined information from ${ }^{18} \mathrm{~F}$-FDG PET and diffusion-weighted MRI led to tumor resection and histologic confirmation of MPNST.

potential role of radiomic analyses on PET and MR images for the detection of MPNST $(46,51)$.

First studies investigating the value of integrated ${ }^{18} \mathrm{~F}$-FDG PET/MRI in neurofibromatosis type 1 confirmed the diagnostic roles of ${ }^{18} \mathrm{~F}-\mathrm{FDG}$ PET/MRI for lesion characterization and treatment planning $(43,45)$. In addition, these studies emphasize further advantages of PET/MRI over sequential PET/CT and MRI, including optimal alignment of MRI and PET in cases of multiple neurofibromas that are closely related, comprehensive examination of the central nervous system and peripheral lesions in a single examination, and significantly reduced diagnostic radiation exposure for patients who need multiple scans during their lifetime.

Table 1 summarizes PET/MRI basic protocols for pediatric oncology in 4 different medical centers, and Table 2 describes the advantages of PET/MRI over PET/CT in the management of pediatric cancer and predisposition syndromes.

\section{Infection or Inflammatory Diseases in Pediatric Cancer Evaluation}

Both infectious and inflammatory etiologies can coexist in children with cancer and complicate assessment of PET/MRI images. It is critical to be able to recognize entities that are most likely attributed to nonneoplastic causes.

In the head and neck region, a sinusitis, otitis, or odontogenic infection can demonstrate hypermetabolic activity; MRI provides structural and functional contrast in soft tissues, helping in the differential diagnosis with neoplastic lesions.

Intrathoracic infection and inflammation are commonly encountered in pediatric PET/MRI oncologic evaluations; pneumonia can often present as a masslike region and can be recognized on the basis of the segmental distribution of hypermetabolic activity as shown in

TABLE 1

${ }^{18}$ F-FDG PET/MRI Basic Protocols for Pediatric Oncology at 4 Different Medical Centers

\begin{tabular}{|c|c|c|c|}
\hline $\begin{array}{l}\text { Institution, scanner model, } \\
\text { and FOV }\end{array}$ & Basic protocol for children & $\begin{array}{l}\text { PET/MRI acquisition time } \\
\text { and injected dose }\end{array}$ & Chest CT \\
\hline $\begin{array}{l}\text { Children's Hospital of } \\
\text { Philadelphia; GE } \\
\text { Healthcare Signa (TOF); } \\
\text { FOV, WB }\end{array}$ & $\begin{array}{l}\text { WB MRAC axial 3D T1 spoiled } \\
\text { gradient echo (LAVA Flex); } \\
\text { axial FRFSE Flex WB } \\
\text { diffusion-weighted imaging } \\
\text { (b=50, 400, 800) (no } \\
\text { intravenous contrast); local } \\
\text { imaging if required }\end{array}$ & $\begin{array}{l}\text { Varies with patient height; } \\
\text { WB scan; 30-60 min; PET, } \\
3 \mathrm{~min} / \mathrm{bed} \geq 5 \text { y or } 4 \mathrm{~min} / \\
\text { bed }<5 \mathrm{y} ; \text { injected dose, } \\
3.7 \mathrm{MBq} / \mathrm{kg}\end{array}$ & Required \\
\hline $\begin{array}{l}\text { Children's Wisconsin; GE } \\
\text { Healthcare Signa (TOF); } \\
\text { FOV, WB }\end{array}$ & $\begin{array}{l}\text { WB MRAC; axial 3D T1 spoiled } \\
\text { gradient echo (LAVA Flex) } \\
\text { (sagittal and coronal } \\
\text { reformats); axial FRFSE Flex } \\
\text { (no intravenous contrast); } \\
\text { local imaging if required }\end{array}$ & $\begin{array}{l}\text { Varies with patient height; } \\
\text { WB scan < } 30 \text { min; PET, } 3 \\
\text { min/bed; injected dose: } \\
2.96 \mathrm{MBq} / \mathrm{kg}\end{array}$ & Only for small lung lesions \\
\hline $\begin{array}{l}\text { University of Tübingen; } \\
\text { Siemens Biograph mMR; } \\
\text { FOV, WB }\end{array}$ & $\begin{array}{l}\text { WB MRAC; contrast-enhanced } \\
\text { axial 3D T1 Dixon spoiled } \\
\text { gradient echo (VIBE); WB } \\
\text { STIR coronal; WB DWI (b = } \\
50,800) \text {; local imaging if } \\
\text { required }\end{array}$ & $\begin{array}{l}\text { Varies with patient height; } \\
\text { WB scan, 45-90 min; PET, } \\
6 \mathrm{~min} / \mathrm{bed} \text {; injected dose, } \\
3.7 \mathrm{MBq} / \mathrm{kg}\end{array}$ & $\begin{array}{l}\text { Only if therapeutic } \\
\text { consequence is } \\
\text { possible (e.g., resection } \\
\text { of lung metastases in } \\
\text { sarcoma) }\end{array}$ \\
\hline $\begin{array}{l}\text { Stanford University; GE } \\
\text { Healthcare Signa (TOF); } \\
\text { FOV, WB }\end{array}$ & $\begin{array}{l}\text { WB MRAC; contrast-enhanced } \\
\text { axial 3D T1 spoiled gradient } \\
\text { echo (LAVA Flex); axial } \\
\text { FRFSE Flex; WB DWI (b = } \\
50,600 \text { or } 800) \text {; local imaging } \\
\text { if required }\end{array}$ & $\begin{array}{l}\text { Varies with patient height; } \\
\text { WB scan, } 60-90 \text { min; } \\
\text { PET, } 4 \mathrm{~min} / \mathrm{bed} \text {; injected } \\
\text { dose, } 3.7 \mathrm{MBq} / \mathrm{kg}\end{array}$ & $\begin{array}{l}\text { Only if therapeutic } \\
\text { consequence is } \\
\text { possible }\end{array}$ \\
\hline \multicolumn{4}{|c|}{$\begin{array}{l}\text { Typical WB PET/CT acquisition time for protocols mentioned in table is less than } 30 \text { min. } \\
\text { TOF = time of flight; FOV = field of view; } \mathrm{WB}=\text { whole body; MRAC = MRI attenuation correction; } 3 \mathrm{D}=3 \text {-dimensional; T1 = T1-weighted; } \\
\text { AVA = Dixon liver acquisition with volume acquisition; Flex = fat/water separation; FRFSE = fast relaxation fast spin echo; bed = bed } \\
\text { sition; VIBE = volumetric interpolated breath-hold examination; DWI = diffusion-weighted imaging; STIR = short-inversion-time inversion } \\
\text { covery. }\end{array}$} \\
\hline
\end{tabular}


TABLE 2

Advantages of PET/MRI over PET/CT

\begin{tabular}{|c|c|}
\hline Tumor type & Advantage \\
\hline \multirow[t]{6}{*}{ Overall } & Simultaneous PET and MRI acquisition (precise registration of MRI and PET) \\
\hline & One-stop local and whole-body staging \\
\hline & Decreased ionizing radiation \\
\hline & Reduced number of total examinations \\
\hline & Better characterization of incidental findings \\
\hline & More accurate measurement of lesions than with unenhanced CT \\
\hline \multirow[t]{3}{*}{ Lymphoma } & Increased sensitivity to detect bone marrow involvement \\
\hline & Avoidance of core biopsy if PET/MRI results are negative \\
\hline & $\begin{array}{l}\text { Reduced dose of ionizing radiation (particularly important for patients with therapy-refractory disease } \\
\text { who need multiple scans to closely monitor treatment efficacy) }\end{array}$ \\
\hline \multirow{3}{*}{$\begin{array}{l}\text { Neurofibromatosis } \\
1 \text { and MPNST }\end{array}$} & Detailed depiction of peripheral neurofibromata and central nervous system \\
\hline & Optimal alignment of MRI and PET in cases of multiple neurofibromas \\
\hline & Comprehensive examination of central nervous system and peripheral lesions in single examination \\
\hline \multirow[t]{3}{*}{ Sarcoma } & Better characterization of bones and soft tissues \\
\hline & Higher sensitivity for bone marrow metastases \\
\hline & Improved monitoring of pediatric tumors after immunotherapy \\
\hline
\end{tabular}

Supplemental Figure 1 (supplemental materials are available at http://jnm.snmjournals.org) (52). Radiation pneumonitis is another acute inflammatory process that needs to be recognized and usually occurs about 3-6 mo after completion of radiotherapy.

In the gastrointestinal system, gastritis, enteritis, appendicitis, and colitis can present as diffuse segmental hypermetabolic activity (53). MRI can help in differentiating ${ }^{18}$ F-FDG activity in the abdomen, by the assessment of mural signal intensity and enhancement specific to both active and chronic inflammatory changes (54).

There are a wide range of infectious and inflammatory conditions that can present with hypermetabolic activity on ${ }^{18} \mathrm{~F}$-FDG PET/MRI pediatric evaluations. Differentiating infectious findings from neoplasms is critical to avoid mischaracterization and to expedite symptom management.

\section{RESEARCH APPLICATIONS OF PET/MRI IN CHILDREN WITH CANCER}

\section{Identifying Responders to New Immunotherapies Can Improve Outcomes}

Integration of molecular and cellular immunotherapies in oncologic practice has transformed cancer treatment. Immunotherapeutic antibodies that include anti-programmed death-ligand 1 (55) and cell-based agents, such as chimeric antigen receptors $\mathrm{T}$ cells $(56)$, aim to redirect the immune system to eradicate tumors. Molecular imaging methods can classify responders and nonresponders, monitor on/off target effects, and elucidate the mechanism of action and distribution of cellular therapeutics.

Radiotracer-based techniques have been used for many years to label white blood cells and detect inflammation $(57,58)$. Therapeutic immune cells can be directly radiolabeled for PET imaging (59) or labeled with iron oxide nanoparticles for MRI (60). These rapid and relatively simple methods do not require genetic manipulation. However, dilution or efflux of the label can result in signal dissipation, thereby limiting the imaging time course. By contrast, reporter gene imaging enables long-term measurements of the biologic fate of the therapeutic cells $(61,62)$. The most commonly used PET reporter gene for visualizing $\mathrm{T}$ cells is the herpes simplex virus type 1 thymidine kinase (63). Although genetic modification of immune cells with reporter genes ensures the propagation of the gene to daughter cells during cellular division, immunogenicity in patients has been observed (64).

Assessments of responses to cancer immunotherapy incorporate existing RECIST (65) and immune-related RECIST used in immunotherapy trials (66). Immunotherapy can lead to immune cell activation in the tumor, transient tumor swelling, increased MRI contrast enhancement, and increased ${ }^{18}$ F-FDG metabolic activity in solid tumors, referred to as pseudoprogression $(67,68)$. Advanced PET/MRI approaches might help to differentiate tumor progression from pseudoprogession (69).

The use of clinical PET/MRI to image immunotherapy response is described in Supplemental Figure 2 (70).

\section{Theranostics for Children}

Classic chemotherapy affects both tumors and normal tissues, leading to significant side effects. New receptor-targeted therapeutics, including small chemical molecules and peptides, antibodies, and nanoparticles, have recently gained a lot of attention (71) because they provide higher molecular-target specificity, increased tumor accumulation, and fewer side effects. Theranostic agents, which comprise a diagnostic and a therapeutic drug, can be used for patient stratification and image-guided therapy. Both PET and MRI theranostic agents have been studied in children with cancer (72-74). From the PET side, DOTATATE compounds have recently been evaluated in children with refractory neuroblastoma (72). A high correlation between ${ }^{68} \mathrm{Ga}$-DOTATATE PET findings and somatostatin receptor type 2 expression in the tumor was reported, and the subsequent peptide receptor radionuclide therapy showed promising results (72). An example of ${ }^{68} \mathrm{Ga}$-DOTATATE PET/ MRI is shown in Supplemental Figure 3. 
From the MRI side, superparamagnetic iron oxide nanoparticles can be used to carry therapeutic drugs or genes into tumors (73), and both radiolabeled and iron-labeled nanoparticles have been used for imaging of TAM (74). Integration of these TAM imaging approaches into whole-body PET/MRI restaging protocols would allow monitoring of both metabolic and TAM responses to immunotherapy in a single examination.

Novel hybrid PET/MRI contrast agents (created by adding a radioisotope to an MRI contrast agent) are under development in preclinical settings (75). So far, they have been tested mostly for stem cell monitoring, Wilms tumor, and tumor angiogenesis (75) and might be used in the future as theranostic agents.

\section{CONCLUSION}

PET/MRI is a safe, sensitive, and efficient imaging technology for cancer evaluation in children, combining metabolic information with high spatial resolution and high soft-tissue contrast while reducing radiation exposure compared with PET/CT. Performing PET/ MRI as a 1-stop imaging technique reduces the need for repetitive anesthesia or sedation and decreases the overall scan time as compared with performing the 2 imaging studies separately.

Integrated PET/MRI is useful for staging and restaging of solid tumors in children and may be helpful for assessing response to novel immunotherapies. Novel developments include personalized treatments with theranostic nanoparticles and radiolabeled peptides. Future directions should focus on improving the detection of small pulmonary nodules, the time- and cost-effectiveness of combined whole-body and local scans, and accessibility to them.

\section{REFERENCES}

1. Pearce MS, Salotti JA, Little MP, et al. Radiation exposure from CT scans in childhood and subsequent risk of leukaemia and brain tumours: a retrospective cohort study. Lancet. 2012;380:499-505.

2. Mathews JD, Forsythe AV, Brady Z, et al. Cancer risk in 680,000 people exposed to computed tomography scans in childhood or adolescence: data linkage study of 11 million Australians. BMJ. 2013;346:f2360.

3. Brenner DJ, Doll R, Goodhead DT, et al. Cancer risks attributable to low doses of ionizing radiation: assessing what we really know. Proc Natl Acad Sci USA. 2003;100: 13761-13766.

4. Hall EJ, Brenner DJ. Cancer risks from diagnostic radiology. Br J Radiol. 2008;81: $362-378$.

5. Robbins E. Radiation risks from imaging studies in children with cancer. Pediatr Blood Cancer. 2008;51:453-457.

6. Schäfer JF, Gatidis S, Schmidt H, et al. Simultaneous whole-body PET/MR imaging in comparison to PET/CT in pediatric oncology: initial results. Radiology. 2014;273: 220-231.

7. Vanderby SA, Babyn PS, Carter MW, Jewell SM, McKeever PD. Effect of anesthesia and sedation on pediatric MR imaging patient flow. Radiology. 2010;256:229-237.

8. Spijkers S, Littooij AS, Nievelstein RAJ. Measurements of cervical lymph nodes in children on computed tomography. Pediatr Radiol. 2020;50:534-542.

9. Vali R, Bakkari A, Marie E, Kousha M, Charron M, Shammas A. FDG uptake in cervical lymph nodes in children without head and neck cancer. Pediatr Radiol. 2017;47: $860-867$.

10. Latifoltojar A, Humphries PD, Menezes LJ, et al. Whole-body magnetic resonance imaging in paediatric Hodgkin lymphoma: evaluation of quantitative magnetic resonance metrics for nodal staging. Pediatr Radiol. 2019;49:1285-1298.

11. Muehe AM, Siedek F, Theruvath AJ, et al. Differentiation of benign and malignant lymph nodes in pediatric patients on ferumoxytol-enhanced PET/MRI. Theranostics. 2020;10:3612-3621.

12. Bartlett ES, Walters TD, Yu E. Can axial-based nodal size criteria be used in other imaging planes to accurately determine "enlarged" head and neck lymph nodes? ISRN Otolaryngol. 2013;2013:232968.

13. Gawande RS, Khurana A, Messing S, et al. Differentiation of normal thymus from anterior mediastinal lymphoma and lymphoma recurrence at pediatric PET/CT. Radiology. 2012;262:613-622.
14. Jerushalmi J, Frenkel A, Bar-Shalom R, Khoury J, Israel O. Physiologic thymic uptake of ${ }^{18}$ F-FDG in children and young adults: a PET/CT evaluation of incidence, patterns, and relationship to treatment. $J$ Nucl Med. 2009;50:849-853.

15. Daldrup-Link HE, Franzius C, Link TM, et al. Whole-body MR imaging for detection of bone metastases in children and young adults: comparison with skeletal scintigraphy and FDG PET. AJR. 2001;177:229-236.

16. Voltin CA, Goergen H, Baues C, et al. Value of bone marrow biopsy in Hodgkin lymphoma patients staged by FDG PET: results from the German Hodgkin Study Group trials HD16, HD17, and HD18. Ann Oncol. 2018;29:1926-1931.

17. Dahlsgaard-Wallenius SE, Hildebrandt MG, Johansen A, et al. Hybrid PET/MRI in non-small cell lung cancer (NSCLC) and lung nodules: a literature review. Eur J Nucl Med Mol Imaging. 2021;48:584-591.

18. Barrington SF, Mikhaeel NG, Kostakoglu L, et al. Role of imaging in the staging and response assessment of lymphoma: consensus of the International Conference on Malignant Lymphomas Imaging Working Group. J Clin Oncol. 2014;32:3048-3058.

19. Ward E, DeSantis C, Robbins A, Kohler B, Jemal A. Childhood and adolescent cancer statistics, 2014. CA Cancer J Clin. 2014;64:83-103.

20. Sher AC, Seghers V, Paldino MJ, et al. Assessment of sequential PET/MRI in comparison with PET/CT of pediatric lymphoma: a prospective study. AJR. 2016;206: 623-631.

21. Ponisio MR, McConathy J, Laforest R, Khanna G. Evaluation of diagnostic performance of whole-body simultaneous PET/MRI in pediatric lymphoma. Pediatr Radiol. 2016;46:1258-1268.

22. Heacock L, Weissbrot J, Raad R, et al. PET/MRI for the evaluation of patients with lymphoma: initial observations. AJR. 2015;204:842-848.

23. Lyons K, Seghers V, Sorensen JI, et al. Comparison of standardized uptake values in normal structures between PET/CT and PET/MRI in a tertiary pediatric hospital: a prospective study. AJR. 2015;205:1094-1101.

24. Badr S, Kotb M, Elahmadawy MA, Moustafa H. Predictive value of FDG PET/CT versus bone marrow biopsy in pediatric lymphoma. Clin Nucl Med. 2018;43:e428e438.

25. Subhawong TK, Jacobs MA, Fayad LM. Diffusion-weighted MR imaging for characterizing musculoskeletal lesions. Radiographics. 2014;34:1163-1177.

26. Hayashida Y, Yakushiji T, Awai K, et al. Monitoring therapeutic responses of primary bone tumors by diffusion-weighted image: initial results. Eur Radiol. 2006; 16:2637-2643.

27. Oka K, Yakushiji T, Sato H, Hirai T, Yamashita Y, Mizuta H. The value of diffusionweighted imaging for monitoring the chemotherapeutic response of osteosarcoma: a comparison between average apparent diffusion coefficient and minimum apparent diffusion coefficient. Skeletal Radiol. 2010;39:141-146.

28. Theruvath AJ, Siedek F, Muehe AM, et al. Therapy response assessment of pediatric tumors with whole-body diffusion-weighted MRI and FDG PET/MRI. Radiology. 2020;296:143-151.

29. Byun BH, Kong CB, Lim I, et al. Combination of ${ }^{18}$ F-FDG PET/CT and diffusionweighted MR imaging as a predictor of histologic response to neoadjuvant chemotherapy: preliminary results in osteosarcoma. J Nucl Med. 2013;54:1053-1059.

30. Daldrup-Link HE. 10 things you might not know about iron oxide nanoparticles. Radiology. 2017;284:616-629.

31. Daldrup-Link HE, Rummeny EJ, Ihssen B, Kienast J, Link TM. Iron-oxide-enhanced MR imaging of bone marrow in patients with non-Hodgkin's lymphoma: differentiation between tumor infiltration and hypercellular bone marrow. Eur Radiol. 2002; 12:1557-1566

32. Mohanty S, Yerneni K, GraefCM, et al. Imaging therapy response of osteosarcoma to anti-CD47 therapy. Cell Death Dis. 2019;10:36-49.

33. Mohanty S, Aghighi M, Yerneni K, Theruvath JL, Daldrup-Link HE. Improving the efficacy of osteosarcoma therapy: combining drugs that turn cancer cell 'don't eat me' signals off and 'eat me' signals on. Mol Oncol. 2019;13:2049-2061.

34. Majeti R, Chao MP, Alizadeh AA, et al. CD47 is an adverse prognostic factor and therapeutic antibody target on human acute myeloid leukemia stem cells. Cell. 2009;138:286-299.

35. Chao MP, Alizadeh AA, Tang C, et al. Anti-CD47 antibody synergizes with rituximab to promote phagocytosis and eradicate non-Hodgkin lymphoma. Cell. 2010; 142:699-713.

36. Edris B, Weiskopf K, Volkmer AK, et al. Antibody therapy targeting the CD47 protein is effective in a model of aggressive metastatic leiomyosarcoma. Proc Natl Acad Sci USA. 2012;109:6656-6661.

37. Chao MP, Jaiswal S, Weissman-Tsukamoto R, et al. Calreticulin is the dominant prophagocytic signal on multiple human cancers and is counterbalanced by CD47. Sci Transl Med. 2010;2:63ra94.

38. Chao MP, Alizadeh AA, Tang C, et al. Therapeutic antibody targeting of CD47 eliminates human acute lymphoblastic leukemia. Cancer Res. 2011;71:1374-1384.

39. Herrmann D, Seitz G, Fuchs J, Armeanu-Ebinger S. Susceptibility of rhabdomyosarcoma cells to macrophage-mediated cytotoxicity. OncoImmunology. 2012;1:279286 
40. Mohanty S, Yerneni K, Theruvath JL, et al. Nanoparticle enhanced MRI can monitor macrophage response to CD47 mAb immunotherapy in osteosarcoma. Cell Death Dis. 2019;10:36.

41. Aghighi M, Theruvath AJ, Pareek A, et al. Magnetic resonance imaging of tumorassociated macrophages: clinical translation. Clin Cancer Res. 2018;24:4110-4118.

42. Daldrup-Link HE, Golovko D, Ruffell B, et al. MRI of tumor-associated macrophages with clinically applicable iron oxide nanoparticles. Clin Cancer Res. 2011; 17:5695-5704.

43. Reinert CP, Schuhmann MU, Bender B, et al. Comprehensive anatomical and functional imaging in patients with type I neurofibromatosis using simultaneous FDGPET/MRI. Eur J Nucl Med Mol Imaging. 2019;46:776-787.

44. Well L, Salamon J, Kaul MG, et al. Differentiation of peripheral nerve sheath tumors in patients with neurofibromatosis type 1 using diffusion-weighted magnetic resonance imaging. Neuro Oncol. 2019;21:508-516.

45. Raad RA, Lala S, Allen JC, et al. Comparison of hybrid ${ }^{18}$ F-fluorodeoxyglucose positron emission tomography/magnetic resonance imaging and positron emission tomography/computed tomography for evaluation of peripheral nerve sheath tumors in patients with neurofibromatosis type 1. World J Nucl Med. 2018;17:241-248.

46. Cook GJR, Lovat E, Siddique M, Goh V, Ferner R, Warbey VS. Characterisation of malignant peripheral nerve sheath tumours in neurofibromatosis-1 using heterogeneity analysis of ${ }^{18}$ F-FDG PET. Eur J Nucl Med Mol Imaging. 2017;44:1845-1852.

47. Salamon J, Derlin T, Bannas P, et al. Evaluation of intratumoural heterogeneity on ${ }^{18}$ F-FDG PET/CT for characterization of peripheral nerve sheath tumours in neurofibromatosis type 1. Eur J Nucl Med Mol Imaging. 2013;40:685-692.

48. Ferner RE, Golding JF, Smith M, et al. $\left[{ }^{18} \mathrm{~F}\right] 2$-fluoro-2-deoxy-D-glucose positron emission tomography (FDG PET) as a diagnostic tool for neurofibromatosis 1 (NF1) associated malignant peripheral nerve sheath tumours (MPNSTs): a longterm clinical study. Ann Oncol. 2008;19:390-394.

49. Yu YH, Wu JT, Ye J, Chen MX. Radiological findings of malignant peripheral nerve sheath tumor: reports of six cases and review of literature. World JSurg Oncol. 2016; $14: 142$.

50. Ahlawat S, Fayad LM. Imaging cellularity in benign and malignant peripheral nerve sheath tumors: utility of the "target sign" by diffusion weighted imaging. Eur J Radiol. 2018;102:195-201.

51. Uthoff J, De Stefano FA, Panzer K, et al. Radiomic biomarkers informative of cancerous transformation in neurofibromatosis-1 plexiform tumors. $J$ Neuroradiol. 2019;46:179-185.

52. Giraudo C, Evangelista L, Fraia AS, et al. Molecular imaging of pulmonary inflammation and infection. Int J Mol Sci. 2020;21:894.

53. Frickenstein AN, Jones MA, Behkam B, McNally LR. Imaging inflammation and infection in the gastrointestinal tract. Int J Mol Sci. 2019;21:243.

54. Sollini M, Berchiolli R, Kirienko M, et al. PET/MRI in infection and inflammation. Semin Nucl Med. 2018;48:225-241.

55. Hoos A. Development of immuno-oncology drugs: from CTLA4 to PD1 to the next generations. Nat Rev Drug Discov. 2016;15:235-247.

56. Maldini CR, Ellis GI, Riley JL. CAR T cells for infection, autoimmunity and allotransplantation. Nat Rev Immunol. 2018;18:605-616.
57. Thakur ML. Immunoscintigraphic imaging of inflammatory lesions: preliminary findings and future possibilities. Semin Nucl Med. 1990;20:92-98.

58. Williams LE. Anniversary paper: nuclear medicine: fifty years and still counting. Med Phys. 2008;35:3020-3029.

59. Weist MR, Starr R, Aguilar B, et al. PET of adoptively transferred chimeric antigen receptor T cells with ${ }^{89} \mathrm{Zr}$-oxine. J Nucl Med. 2018;59:1531-1537.

60. Kircher MF, Allport JR, Graves EE, et al. In vivo high resolution three-dimensional imaging of antigen-specific cytotoxic T-lymphocyte trafficking to tumors. Cancer Res. 2003;63:6838-6846.

61. Larimer BM. Reporter genes for PET imaging of CAR T cells offers insight into adoptive cell transfer. J Nucl Med. 2018;59:1892-1893.

62. Krebs S, Ahad A, Carter LM, et al. Antibody with infinite affinity for in vivo tracking of genetically engineered lymphocytes. J Nucl Med. 2018;59:1894-1900.

63. Keu KV, Witney TH, Yaghoubi S, et al. Reporter gene imaging of targeted T cell immunotherapy in recurrent glioma. Sci Transl Med. 2017;9:eaag2196.

64. Riddell SR, Elliott M, Lewinsohn DA, et al. T-cell mediated rejection of genemodified HIV-specific cytotoxic T lymphocytes in HIV-infected patients. Nat Med. 1996;2:216-223.

65. Eisenhauer EA, Therasse $\mathrm{P}$, Bogaerts J, et al. New response evaluation criteria in solid tumours: revised RECIST guideline (version 1.1). Eur J Cancer. 2009;45:228-247.

66. Seymour L, Bogaerts J, Perrone A, et al. iRECIST: guidelines for response criteria for use in trials testing immunotherapeutics. Lancet Oncol. 2017;18:e143-e152.

67. Brandsma D, Stalpers L, Taal W, Sminia P, van den Bent MJ. Clinical features, mechanisms, and management of pseudoprogression in malignant gliomas. Lancet Oncol. 2008;9:453-461.

68. Hygino da Cruz LC Jr, Rodriguez I, Domingues RC, Gasparetto EL, Sorensen AG. Pseudoprogression and pseudoresponse: imaging challenges in the assessment of posttreatment glioma. AJNR. 2011;32:1978-1985.

69. Kasten BB, Udayakumar N, Leavenworth JW, et al. Current and future imaging methods for evaluating response to immunotherapy in neuro-oncology. Theranostics. 2019;9:5085-5104.

70. Yaghoubi SS, Jensen MC, Satyamurthy N, et al. Noninvasive detection of therapeutic cytolytic T cells with ${ }^{18} \mathrm{~F}$-FHBG PET in a patient with glioma. Nat Clin Pract Oncol. 2009;6:53-58.

71. Pruis IJ, van Dongen G, Veldhuijzen van Zanten SEM. The added value of diagnostic and theranostic PET imaging for the treatment of CNS tumors. Int J Mol Sci. 2020; 21:1029.

72. Kong G, Hofman MS, Murray WK, et al. Initial experience with gallium-68 DOTAoctreotate PET/CT and peptide receptor radionuclide therapy for pediatric patients with refractory metastatic neuroblastoma. J Pediatr Hematol Oncol. 2016;38:87-96.

73. Li K, Nejadnik H, Daldrup-Link HE. Next-generation superparamagnetic iron oxide nanoparticles for cancer theranostics. Drug Discov Today. 2017;22:1421-1429.

74. Mukherjee S, Sonanini D, Maurer A, Daldrup-Link HE. The yin and yang of imaging tumor associated macrophages with PET and MRI. Theranostics. 2019;9:7730-7748.

75. Kiani A, Esquevin A, Lepareur N, Bourguet P, Le Jeune F, Gauvrit J. Main applications of hybrid PET-MRI contrast agents: a review. Contrast Media Mol Imaging. 2016;11:92-98. 